\title{
Copeptin concentration in cord blood in infants with early-onset sepsis, chorioamnionitis and perinatal asphyxia
}

Luregn J Schlapbach ${ }^{*}$, Stefanie Frey ${ }^{1}$, Susanna Bigler ${ }^{2}$, Chiem Manh-Nhi $^{3}$, Christoph Aebi ${ }^{1,2}$, Mathias Nelle ${ }^{1}$ and Jean-Marc Nuoffer ${ }^{1,3}$

\begin{abstract}
Background: Vasopressin is one of the most important physiological stress and shock hormones. Copeptin, a stable vasopressin precursor, is a promising sepsis marker in adults. In contrast, its involvement in neonatal diseases remains unknown. The aim of this study was to establish copeptin concentrations in neonates of different stress states such as sepsis, chorioamnionitis and asphyxia.

Methods: Copeptin cord blood concentration was determined using the BRAHMS kryptor assay. Neonates with early-onset sepsis (EOS, $n=30)$, chorioamnionitis $(n=33)$ and asphyxia $(n=25)$ were compared to a control group of preterm and term $(n=155)$ neonates.

Results: Median copeptin concentration in cord blood was $36 \mathrm{pmol} / \mathrm{l}$ ranging from undetectable to $5498 \mathrm{pmol} / \mathrm{l}$ (IQR 7 - 419). Copeptin cord blood concentrations were non-normally distributed and increased with gestational age $(p<0.0001)$. Neonates born after vaginal compared to cesarean delivery had elevated copeptin levels $(p<$ 0.0001). Copeptin correlated strongly with umbilical artery pH (Spearman's Rho $-0.50, p<0.0001$ ), umbilical artery base excess (Rho -0.67, p < 0.0001) and with lactate at NICU admission (Rho 0.54, p<0.0001). No difference was found when comparing copeptin cord blood concentrations between neonates with EOS and controls (multivariate $\mathrm{p}=0.30$ ). The highest copeptin concentrations were found in neonates with asphyxia (median 993 pmol/l). Receiver-operating-characteristic curve analysis showed that copeptin cord blood concentrations were strongly associated with asphyxia: the area under the curve resulted at 0.91 (95\%-Cl 0.87-0.96, p < 0.0001). A cut-off of $400 \mathrm{pmol} / \mathrm{l}$ had a sensitivity of $92 \%$ and a specifity of $82 \%$ for asphyxia as defined in this study.
\end{abstract}

Conclusions: Copeptin concentrations were strongly related to factors associated with perinatal stress such as birth acidosis, asphyxia and vaginal delivery. In contrast, copeptin appears to be unsuitable for the diagnosis of EOS.

Keywords: asphyxia early-onset sepsis, copeptin, neonate, vasopressin

\section{Background}

Arginine vasopressin (or antidiuretic hormone, ADH), is a nonapeptide acting as a main regulator in the homeostatis of the cardiovascular and renal system [1]. It is produced by the hypothalamus and secreted in the posterior lobe of the pituitary gland upon hemodynamic or osmotic stimuli. Vasopressin plays a crucial role in

\footnotetext{
* Correspondence: luregn.schlapbach@gmail.com

'Neonatal and Pediatric Intensive Care Unit, Department of Pediatrics, University of Bern, 3010 Bern, Switzerland

Full list of author information is available at the end of the article
}

the endocrine stress response to a variety of diseases such as different shock states [2]. Exogenous vasopressin is a promising therapeutic agent in cardiac arrest and septic shock in adults [3]. A recent multicenter randomized controlled trial evaluated low-dose vasopressin in pediatric vasodilatory shock [4]. Although few authors have reported successful use of vasopressin in neonates with arterial hypotension [5-8], data on the role of vasopressin during the neonatal period are scarce.

Since vasopressin is highly instable with a short halflife of 4-20 minutes [1], reliable determination of

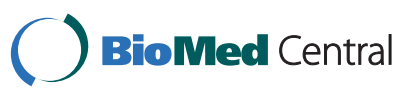


vasopressin concentration is not used in clinical practice. Vasopressin is derived from a larger precursor peptide which contains also C-terminal pro-vasopressin, called copeptin [9]. Upon release of vasopressin, equal amounts of copeptin are secreted. Copeptin is relatively stable in serum and thereby reliably mirrors vasopressin levels $[10,11]$. Copeptin concentrations were strongly elevated in samples from adult patients with sepsis $[9,12,13]$ and high copeptin levels were predictive of mortality $[12,14]$. Recent studies in adults have shown that copeptin is a valuable biomarker of infection in patients with community-acquired and ventilator-associated pneumonia [14].

Wellmann et al. have recently provided normal values for healthy term and near-term infants [15], but, to the best of our knowledge, copeptin has never been investigated in neonates with major diseases. We hypothesized that copeptin cord blood concentrations in neonates may be associated with different stress situations such as sepsis and perinatal asphyxia.

Neonatal infections account for over one million neonatal deaths worldwide every year [16]. Early-onset sepsis (EOS, presenting within 72 hours of age) occurs in approximately $0.6 \%$ of term and up to $1.5 \%$ of preterm infants and contributes significantly to neonatal mortality [17]. Therefore, early treatment of neonates with suspected infection is crucial to prevent life threatening complications. New infection markers may potentially improve guidance of therapeutic decisions [18].

Perinatal asphxia is, after prematurity and sepsis, the third main cause of neonatal death worldwide [19]. While therapeutic hypothermia has proven to improve survival and to reduce the rate of disability, mortality due to severe perinatal hypoxic-ischemic encephalopathy remains high even in developed countries [20].

This study therefore aimed to establish copeptin cord blood concentrations in neonates of different gestational ages and to assess the influence of sepsis, chorioamnionitis and asphyxia on copeptin concentrations.

\section{Methods}

Infants born between November 2004 and November 2007 at the Department of Obstetrics, University of Bern, Switzerland, were eligible for this study if cord blood serum had been drawn and stored immediately after birth. Neonates with major congenital malformations were excluded. The study was approved by the institutional Ethical Board (Direktion Lehre und Forschung, Inselspital, University of Bern, 3010 Bern, Switzerland).

Patients and controls were searched using the institutional neonatal database. Perinatal characteristics and postnatal parameters were extracted from the institutional neonatal database. Arterial umbilical cord $\mathrm{pH}$ was obtained routinely. Blood gas analyses and hemoglobin concentrations were obtained routinely in neonates admitted to the neonatal intensive care unit (NICU) and were included in this study if they had been obtained within six hours after birth. Small for gestational age (SGA) was defined as infants with a birth weight below the $10^{\text {th }}$ percentile. Arterial hypotension was defined as mean arterial blood pressure which was below the gestational age limit at two consecutive measurements and that was treated with either a volume bolus administration, intravenous corticosteroids or catecholamines.

The following groups were defined: early-onset sepsis group, chorioamnionitis group, asphyxia group, and control group.

\section{Early onset sepsis group (EOS)}

EOS cases were defined as neonates who presented with sepsis within the first 72 hours of life as defined by the following criteria [21]: i) at least two clinical signs of sepsis (temperature instability, irritability or apathy, feeding difficulties, poor capillary refill $>2$ seconds, apnea, tachycardia and/or tachypnea); ii) elevated Creactive protein $>20 \mathrm{mg} / \mathrm{l}$, iii) decision of the attending physician to treat for at least 7 days with intravenous antibiotics and iv) recovery of bacterial pathogens in blood-culture. In infants with negative blood cultures but clinical diagnosis of EOS, all first three criteria mentioned above were required to be present.

\section{Chorioamnionitis group}

Chorioamnionitis was defined as either clinically diagnosed chorioamnionitis (requiring presence of maternal fever, elevated maternal CRP, fetal tachycardia and prolonged rupture of membranes $>24 \mathrm{~h}$ ) or histologically diagnosed chorioamnionitis [22]. Only infants exposed to chorioamnionitis without evidence of neonatal infection as defined above were considered in order to avoid overlap with the EOS group.

\section{Asphyxia group}

Asphyxia was defined according to our institutional guidelines as arterial cord blood pH below 7.1 plus 10-minute Apgar score below 6 and/or base excess $>-12 \mathrm{mmol} / \mathrm{l}$. This definition allowed to include both severe asphyxia [20], and milder forms of asphyxia. In addition, the asphyxia group required absence of clinically or histologically diagnosed chorioamnionitis and of confirmed EOS as defined above in order to avoid overlap with the EOS and the chorioamnionitis group. Hypoxicischemic encephalopathy (HIE) was graded according to Sarnat stage 0 (no HIE) to stage 3 (severe HIE) [23].

\section{Control group}

Based on sample size calculations, a control group of at least 135 controls was required to detect a mean 
difference of $75 \mathrm{pmol} / \mathrm{l}$ between patients and controls with a power of $80 \%$ at a $95 \%$-confidence interval. The assumptions were based on preliminary internal data and on published data from adults with sepsis [24]. The control group $(\mathrm{n}=155)$ consisted of 75 premature neonates (24 0/7 to 36 6/7 weeks gestational age) without neonatal infection, chorioamnionitis or asphyxia (as defined above) and of 80 healthy term neonates (37 0/7 to $420 / 7$ weeks gestational age) with no signs of any neonatal disease. Neonates with major congenital malformations were excluded. The control group infants were all born between January 2007 and November 2007.

\section{Copeptin measurements}

Cord blood is routinely collected immediately after delivery of the child from the umbilical vein at the placental side of the cord, and is routinely stored at our institution to determine Toxoplasma gondii serology in neonates of mothers with unknown or negative serostatus. After centrifugation, cord blood serum was frozen in sterile tubes at $-80^{\circ} \mathrm{C}$. Copeptin cord blood concentrations were determined using the commercial BRAHMS copeptin kryptor assay according to the manufacturer's instructions (BRAHMS, Hennigsdort, Germany). The detection limit of the assay was $4.8 \mathrm{pmol} / \mathrm{l}$.

\section{Statistical analysis}

Copeptin concentrations were compared between patients and controls using Mann-Whitney U test and multivariate linear regression analysis. Multivariate analyses included gestational age, birth weight, SGA, mode of delivery and umbilical artery $\mathrm{pH}$ as covariates. Spearman's rank test and multivariate linear regression were used to analyze association between copeptin cord blood concentration with linear variables. Copeptin cord blood concentrations were logarithmized for regression analyses. Mann-Whitney U-test was used where appropriate. Receiver-operating-characteristic (ROC) curve analysis was used to assess specifity and sensitivity of copeptin for the diagnosis of EOS, chorioamnionitis and asphyxia. Two-sided tests were used throughout, and Pvalues below 0.05 were considered significant. SPSS 18.0 software was used.

\section{Results}

\section{i) Patient characteristics}

During the study period, 3896 neonates were born, 42 of whom fulfilled the EOS criteria. Cord blood serum was available in $30(72 \%)$ neonates with EOS, these were thus included in the study. Their median gestational age was 31 weeks. In eight (27\%) patients, blood cultures resulted positive. Maximum $\mathrm{C}$-reactive protein during sepsis was at median $44 \mathrm{mg} / \mathrm{l}$ (range 22 - 261). Five infants $(17 \%)$ required treatment with catecholamines due to septic shock and two (7\%) infants died during sepsis. The chorioamnionitis group comprised 33 neonates without evidence of neonatal infection with a median gestational age of 30 weeks.

During the study period, 36 neonates were born with asphyxia. Of these, cord blood serum was available in 25 (69\%). Their median gestational age was 37 weeks. Two (8\%) had HIE Sarnat stage 3 and died, three (12\%) Sarnat stage 2, and seven (28\%) Sarnat stage 1, while 13 (52\%) had no signs of HIE. Their median lactate concentration at NICU admission was $10.7 \mathrm{mmol} / \mathrm{l}$ (range 4 - 25).

Baseline characteristics of the patient groups and the control group are given in Table 1.

\section{ii) Copeptin cord blood concentrations in the whole cohort}

When analyzing copeptin cord blood concentrations in the whole study population ( $\mathrm{n}=243)$, median concentration was $36 \mathrm{pmol} / \mathrm{l}$ ranging from undetectable to 5498 pmol/l (IQR 7 - 419). Copeptin concentration correlated significantly with gestational age (Spearman's Rho $0.30, \mathrm{p}<0.0001$, Figure 1), and birth weight (Rho $0.29, \mathrm{p}<0.0001)$, but did not differ between boys and girls (Mann-Whitney Z -10.98, $\mathrm{p}=0.33$ ). Infants after vaginal delivery compared to cesarean delivery had significantly higher copeptin levels (Mann-Whitney Z -7.32, $\mathrm{p}<0.0001$, Figure 2), even when adjusting for gestational age $(\mathrm{p}<0.001)$. Copeptin cord blood concentration showed a strong negative correlation with umbilical artery $\mathrm{pH}$ (Rho $-0.50, \mathrm{p}<0.0001)$ and umbilical artery base excess (Rho $-0.67, \mathrm{p}<0.0001$ ), see Figure 3. Similarly, copeptin concentration correlated strongly with $\mathrm{pH}$ (Rho -0.34, $\mathrm{p}<0.0001$ ) and with lactate at NICU admission (Rho 0.54, p $<0.0001$ ), see Figure 3. The correlations between copeptin and $\mathrm{pH}$, base excess and lactate remained significant in subgroup analyses on very preterm, late preterm and term neonates $(<32$, 32-36 6/7, $\geq 37$ weeks gestational age, $\mathrm{p}<0.05$, details not shown).

No association was found between copeptin cord blood concentrations and arterial hypotension requiring treatment with volume and/or vasopressors, or with hemoglobin concentration and hematocrit at NICU admission ( $\mathrm{p}>0.05)$.

\section{iii) Copeptin cord blood concentrations in neonates with EOS and with chorioamnionitis}

Median copeptin concentrations were $35 \mathrm{pmol} / \mathrm{l}$ (IQR 8 212 ) in the EOS versus $20 \mathrm{pmol} / \mathrm{l}$ (IQR 6 - 139) in the chorioamnionitis group versus $21 \mathrm{pmol} / \mathrm{l}$ (IQR 5 - 324) in controls, see Figure 4. Although median copeptin concentrations were higher in EOS infants compared to controls, this was not statistically significantly (Mann- 
Table 1 Baseline characteristics according to study group

\begin{tabular}{|c|c|c|c|c|}
\hline Study group & $\begin{array}{l}\text { Early-onset sepsis } \\
\quad(\mathrm{N}=30)\end{array}$ & $\begin{array}{c}\text { Chorioamnionitis } \\
(\mathrm{N}=33)\end{array}$ & $\begin{array}{l}\text { Asphyxia } \\
(\mathrm{N}=25)\end{array}$ & $\begin{array}{c}\text { Control } \\
(\mathrm{N}=155)\end{array}$ \\
\hline Gender (male) & $12(40 \%)$ & $12(36 \%)$ & $10(40 \%)$ & $87(56 \%)$ \\
\hline Gestational age [weeks] & $31.5(29-34)$ & $30(28-34)$ & $36.5(33-39)$ & $38(32-40)$ \\
\hline Birth weight [gram] & $1665(1161-2490)$ & 1430 (998-1975) & $2400(1573-3213)$ & $2800(1590-3420)$ \\
\hline Prenatal steroids & $23(77 \%)$ & $27(82 \%)$ & $8(32 \%)$ & $64(41 \%)$ \\
\hline Cesarean section & $18(60 \%)$ & $18(55 \%)$ & $17(68 \%)$ & $73(47 \%)$ \\
\hline PROM $>24 h$ & $7(23 \%)$ & $10(30 \%)$ & $2(8 \%)$ & $16(10 \%)$ \\
\hline SGA & $3(10 \%)$ & $4(12 \%)$ & $7(28 \%)$ & $11(7 \%)$ \\
\hline APGAR $1 \mathrm{~min}$ & $5(3-7)$ & $6(4-8)$ & $3(2-6)$ & $8(6-8)$ \\
\hline APGAR 5 min & $8(6-9)$ & $8(7-9)$ & $7(5-8)$ & $9(8-9)$ \\
\hline APGAR $10 \mathrm{~min}$ & $9(7-9)$ & $9(8-9)$ & $8(7-9)$ & $9(9-9)$ \\
\hline Cord blood arterial pH & $7.30(7.24-7.33)$ & $7.29(7.24-7.33)$ & $7.03(7.00-7.07)$ & $7.29(7.25-7.32)$ \\
\hline PDA & $6(20 \%)$ & $5(15 \%)$ & $0(0 \%)$ & $11(7 \%)$ \\
\hline Arterial hypotension & $12(40 \%)$ & $11(33 \%)$ & $11(44 \%)$ & $32(21 \%)$ \\
\hline Mechanical ventilation & $16(53 \%)$ & $13(39 \%)$ & $8(32 \%)$ & $13(8 \%)$ \\
\hline
\end{tabular}

Median (interquartile range) or number (percentage) are shown.

PDA, persistent ductus arteriosus; PROM, prolonged rupture of membranes; SGA, small for gestational age $\left(<10^{\text {th }}\right.$ percentile)

Whitney Z -0.58, p = 0.56). This was confirmed by multivariate linear regression analysis adjusted for gestational age, birth weight, SGA, delivery mode and umbilical artery $\mathrm{pH}$ (beta coefficient $0.16,95 \%$-CI $-0.14-0.45, \mathrm{p}=$ 0.30 ), Copeptin concentrations did not significantly differ between EOS infants with septic shock or with positive blood cultures compared to the rest of EOS infants ( $p>0.05$ ). ROC curve analysis confirmed that the performance of copeptin to distinguish EOS from controls was poor (area under the curve, 0.53, 95\%-CI 0.44-0.63, p = 0.57). No difference was found when comparing copeptin levels between the chorioamnionitis group and controls or between the chorioamnionitis and the EOS group ( $p>0.1$ ). Copoeptin was not associated with CRP, leukocyte count or left shift (immature by total neutrophil ratio, $\mathrm{p}>0.05$, details not shown).

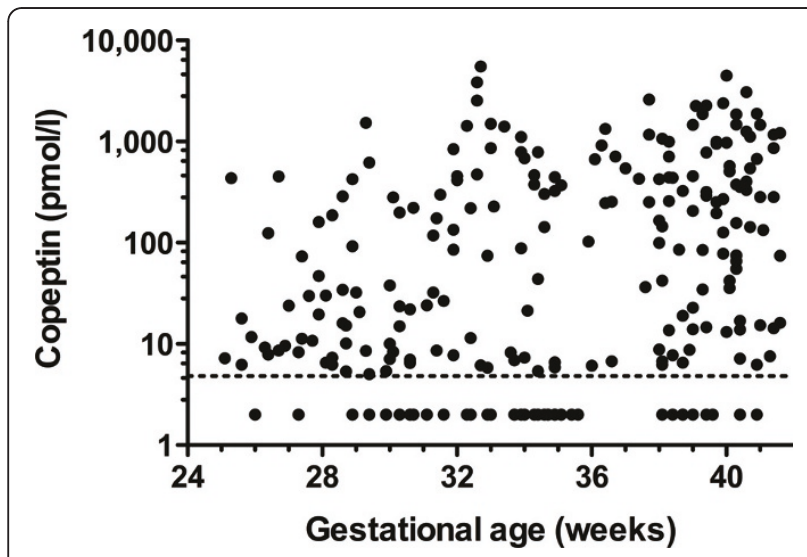

Figure 1 Copeptin and gestational age. Copeptin cord blood concentrations are shown according to gestational age. The dotted line indicates the detection limit (4.8 pmol/l). iv) Copeptin cord blood concentrations in neonates with asphyxia

Copeptin cord blood concentrations were significantly higher in the 25 neonates with asphyxia (median 993 pmol/l, IQR 505 - 2466, range 100 - 5498) compared to controls (Mann-Whitney Z $-6.49, \mathrm{p}<0.0001$ ), see Figure 5 . This was confirmed by multivariate analysis (beta coefficient $1.09,95 \%$-CI $0.41-1.76, \mathrm{p}=0.002$ ). Notably, the eight highest copeptin values measured, all above $2000 \mathrm{pmol} / \mathrm{l}$, occurred in neonates with asphyxia. None of these eight neonates with very high copeptin levels had more than Sarnat stage one HIE, and all survived. Copeptin concentration was not significantly correlated with Sarnat score (Rho $-0.31, \mathrm{p}=0.133$ ).

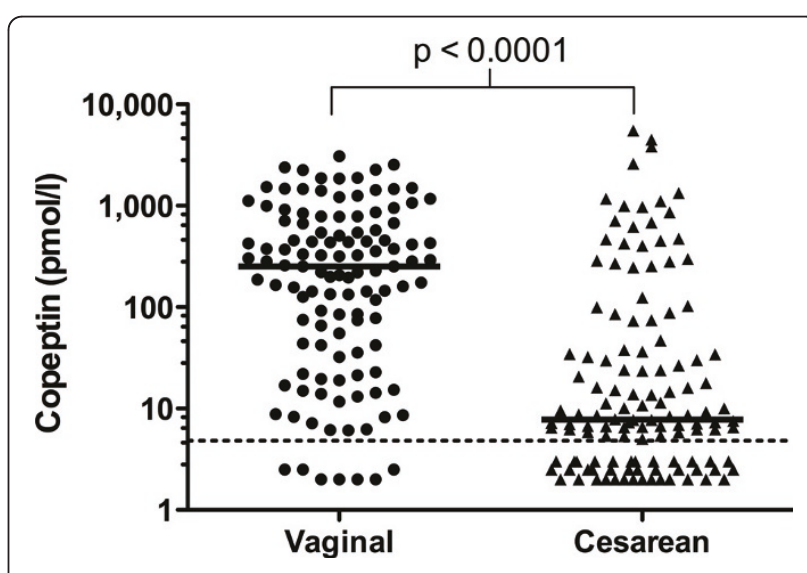

Figure 2 Copeptin concentration is increased after vaginal delivery. Copeptin cord blood concentrations according to the delivery mode are shown. The medians and the p-value of MannWhitney $\mathrm{U}$ test are shown. The dotted line indicates the detection limit $(4.8 \mathrm{pmol} / \mathrm{l})$. 


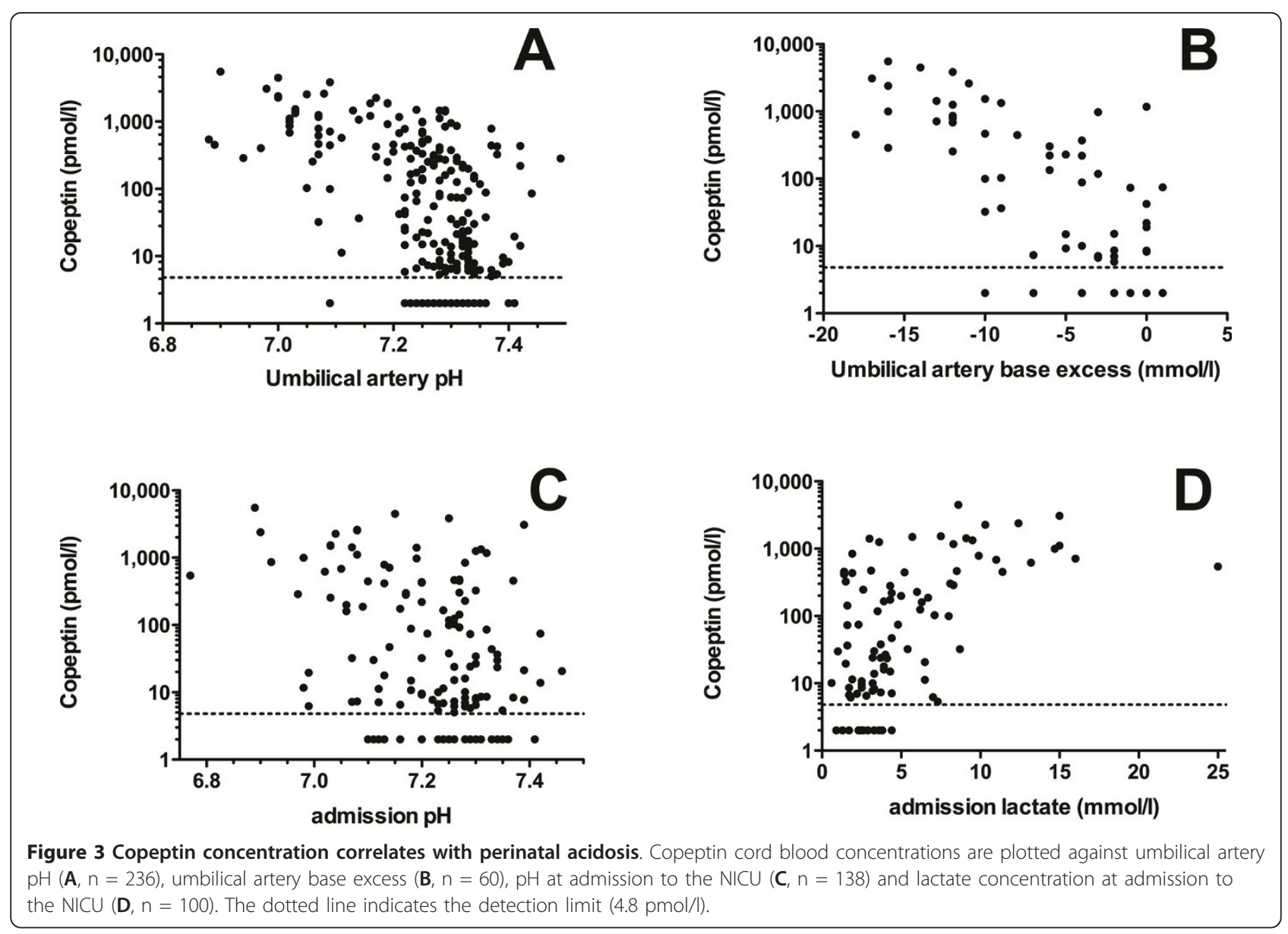

ROC curve analysis showed that copeptin concentrations discriminated with high accuracy between asphyxia, as defined in this study, and controls: the area under the curve resulted at 0.91 (95\%-CI $0.87-0.96$, p $<0.0001$, see Figure 6). A cut-off of $400 \mathrm{pmol} / \mathrm{l} \mathrm{had} \mathrm{a}$ sensitivity of $92 \%$ and a specifity of $82 \%$.

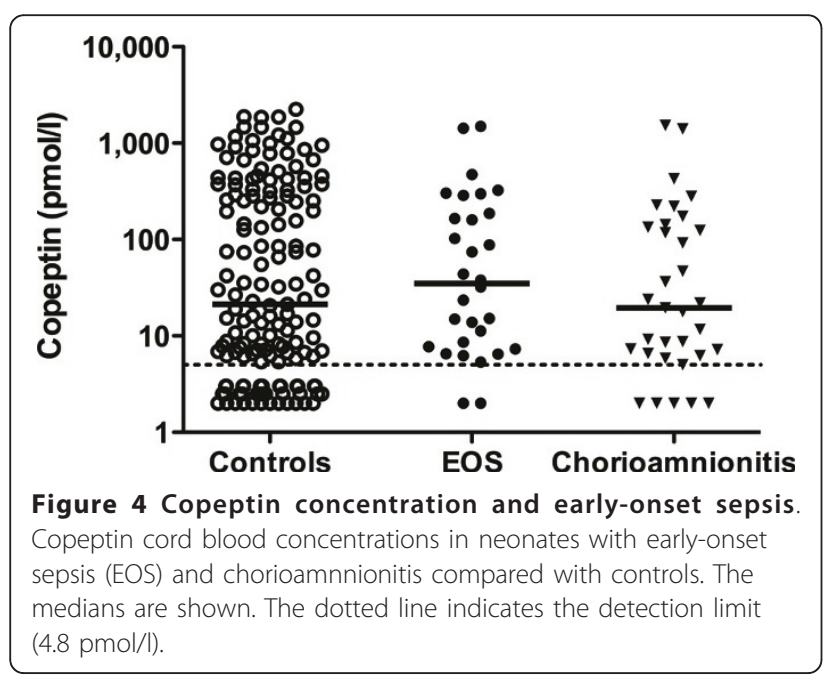

\section{Discussion}

Our findings indicate that copeptin cord blood concentrations reflect perinatal stress with the highest values found in neonates with asphyxia. To the best of our

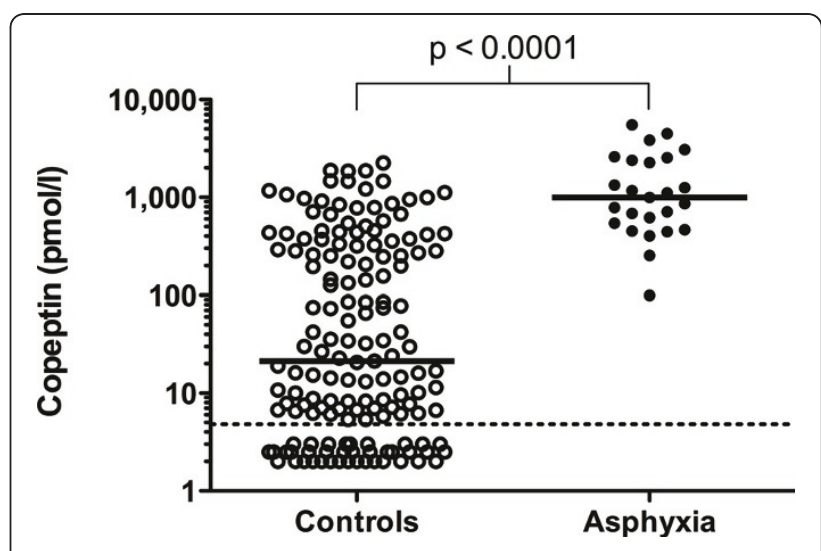

Figure 5 Copeptin concentration in infants with asphyxia. Copeptin cord blood concentrations in neonates with asphyxia compared with controls. The medians and the p-value of ManWhitney $U$ test are shown. The dotted line indicates the detection limit (4.8 pmol/l). 


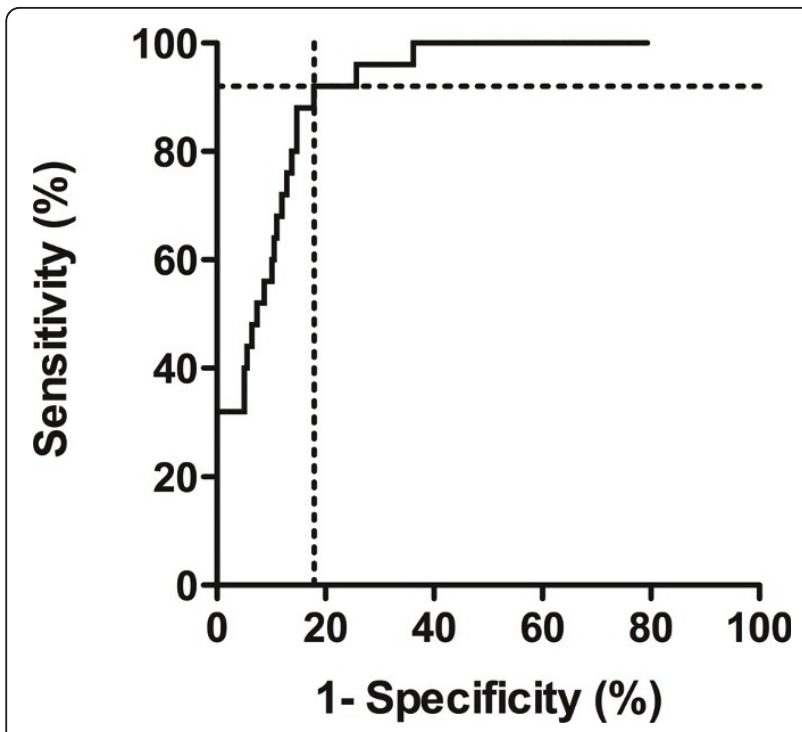

Figure 6 Receiver-operating-characteristic curve of copeptin concentrations in relation to asphyxia. Receiver-operatingcharacteristic curve is shown for copeptin cord blood

concentrations in relation to asphyxia. The dotted lines indicate the optimal discriminative cut-off of $400 \mathrm{pmol} / \mathrm{l}$, resulting in a sensitivity of $92 \%$ and a specifity of $82 \%$.

knowledge, this is the first study to investigate copeptin in newborns with EOS and asphyxia.

Copeptin cord blood concentration was strongly and inversely correlated with umbilical artery $\mathrm{pH}$, umbilical artery base excess, and with $\mathrm{pH}$ and lactate at admission to the NICU. Perinatal acidosis results from diminished fetal blood and oxygen supply due to maternal, placental or cord complications leading to lactic acidosis. Vasopressin is released by the hypothalamus-hypopituitary upon sensing of increased plasma osmolality, decreased arterial pressure, and reductions in cardiac volume [1]. Our data indicate that the vasopressin system in the neonate is strongly activated upon perinatal stress. Importantly, the strength of these correlations was comparable between very preterm, late preterm and term infants, suggesting that the vasopressin response is already present at an early gestational age.

The highest copeptin cord blood concentrations were found in neonates with perinatal asphyxia. This finding was confirmed by multivariate analysis adjusted for gestational age, birth weight, mode of delivery and umbilical artery $\mathrm{pH}$. Most values in this group, a third of them exceeding $2000 \mathrm{pmol} / \mathrm{l}$, were much higher that concentrations that have been reported in adult studies on patients with septic shock, multiple trauma or myocardial infarction $[9,25,26]$. Copeptin cord blood concentrations above $400 \mathrm{pmol} / \mathrm{l}$ had a high sensitivity and specifity for asphyxia. Perinatal asphyxia can be considered as an extreme of a stress situation. In a study on the stress response to hypoxia in neonatal piglets, maintenance of cardiovascular function and a higher serum cortisol concentration were associated with a better neurological outcome [27]. Further studies are needed to determine whether copeptin is related to asphyxia severity and whether copeptin may improve outcome prognostication after asphyxia.

Neonates born by vaginal delivery had significantly elevated copeptin cord blood concentrations compared to those born by cesarean section, even after adjustment for gestational age. Wellmann et al. have recently determined copeptin in 177 neonates and found higher levels after vaginal delivery as well [15]. These findings are in line with earlier reports of elevations in the stress hormone cortisol after vaginal delivery [28]. Spontaneous labour physiologically induces important changes in the fetal homeostatic system which serve to prime the fetus for postnatal adaptation.

Copeptin has been shown to be a valuable infection marker in adults with sepsis and community-acquired pneumonia [9,12-14]. In contrast, in our study, copeptin concentrations in cord blood were not significantly elevated in EOS infants compared to controls. The specifity and sensitivity of copeptin in the diagnosis of EOS was poor. Similarly, no difference was found between neonates born to mothers with chorioamnionitis and controls. Given the strong influence of perinatal stress on copeptin cord blood concentrations, and considering the very large interindividual variations observed in this study, our data indicate that determining copeptin concentrations is not suitable to diagnose EOS. Potentially, the diagnostic accuracy of copeptin may be improved in late-onset infections, since the effect of perinatal stress on copeptin disappears over the first days of life [15].

Several limitations of this study need to be mentioned. Firstly, only neonates where cord blood was available were included. A selection bias is, however, unlikely, since cord blood was routinely collected during the study period in neonates of mothers with unknown or negative Toxoplasma gondii serostatus, a condition which is unlikely to affect copeptin cord blood concentrations. Secondly, the relatively small sample sizes limits statistical power. Therefore, confirmation by future prospective cohorts is needed.

We believe that the present study has several strengths. In contrast to the study by Wellmann et al. [15] which included only healthy term and near term infants, we included neonates with a wide range of gestational ages. The inclusion of clearly defined and not overlapping groups of infants with EOS, chorioamnionitis and asphyxia allowed to study the influence of these diseases on copeptin concentration. Multivariate analyses were adjusted for the main confounders gestational age, birth weight, delivery mode and umbilical artery $\mathrm{pH}$. 


\section{Conclusions}

We report that copeptin concentrations in cord blood are strongly correlated to perinatal stress with the highest values found in neonates with perinatal asphyxia. Future studies should prospectively determine copeptin concentrations in combination with novel markers of neonatal brain damage, such as neuron-specific enolase or S-100B [29-31], in order to investigate whether copeptin concentrations are of prognostic value during asphyxia.

\section{Abbreviations}

CRP: C-reactive protein; EOS: early-onset sepsis; HIE: hypoxic-ischemic encephalopathy; ROC: receiver-operating characteristic

\section{Acknowledgements}

The authors thank Claudia Schad, Division of Neonatology, University of Bern, Switzerland, for help in data acquisition. This study was supported by a grant from the Vinetum Foundation, Biel, Switzerland.

\section{Author details}

${ }^{1}$ Neonatal and Pediatric Intensive Care Unit, Department of Pediatrics, University of Bern, 3010 Bern, Switzerland. Institute for Infectious Diseases, University of Bern, 3010 Bern, Switzerland. ${ }^{3}$ University Institute for Clinical Chemistry, University of Bern, 3010 Bern, Switzerland.

\section{Authors' contributions}

LS had primary responsibility for the study design, data acquisition, analysis and writing the manuscript. SF performed clinical data collection, statistical analyses and helped to draft the manuscript. CA and MN were involved in study design, data acquisition and writing of the manuscript. SB, CM and JMN carried out processing of umbilical cord sera, performed the laboratory analyses and helped to draft the manuscript. All authors have read and approved the final manuscript.

\section{Competing interests}

The authors declare that they have no competing interests.

Received: 18 November 2010 Accepted: 19 May 2011

Published: 19 May 2011

\section{References}

1. Treschan TA, Peters J: The vasopressin system: physiology and clinical strategies. Anesthesiology 2006, 105(3):599-612, quiz 639-540.

2. Choong K, Kissoon N: Vasopressin in pediatric shock and cardiac arrest. Pediatr Crit Care Med 2008, 9(4):372-379.

3. Russell JA, Walley KR, Singer J, Gordon AC, Hebert PC, Cooper DJ, Holmes CL, Mehta S, Granton JT, Storms MM, et al: Vasopressin versus norepinephrine infusion in patients with septic shock. N Engl J Med 2008, 358(9):877-887.

4. Choong K, Bohn D, Fraser DD, Gaboury I, Hutchison JS, Joffe AR, Litalien C, Menon K, McNamara P, Ward RE: Vasopressin in pediatric vasodilatory shock: a multicenter randomized controlled trial. Am J Respir Crit Care Med 2009, 180(7):632-639.

5. Filippi L, Poggi C, Serafini L, Fiorini P: Terlipressin as rescue treatment of refractory shock in a neonate. Acta Paediatr 2008, 97(4):500-502.

6. Matok I, Leibovitch L, Vardi A, Adam M, Rubinshtein M, Barzilay Z, Paret G: Terlipressin as rescue therapy for intractable hypotension during neonatal septic shock. Pediatr Crit Care Med 2004, 5(2):116-118.

7. Meyer S, Gottschling S, Baghai A, Wurm D, Gortner L: Arginine-vasopressin in catecholamine-refractory septic versus non-septic shock in extremely low birth weight infants with acute renal injury. Crit Care 2006, 10(3):R71.

8. Bidegain M, Greenberg R, Simmons C, Dang C, Cotten CM, Smith PB: Vasopressin for refractory hypotension in extremely low birth weight infants. J Pediatr 2010, 157(3):502-504
9. Struck J, Morgenthaler NG, Bergmann A: Copeptin, a stable peptide derived from the vasopressin precursor, is elevated in serum of sepsis patients. Peptides 2005, 26(12):2500-2504.

10. Morgenthaler NG, Struck J, Alonso C, Bergmann A: Assay for the measurement of copeptin, a stable peptide derived from the precursor of vasopressin. Clin Chem 2006, 52(1):112-119.

11. Jochberger S, Velik-Salchner C, Mayr VD, Luckner G, Wenzel V, Falkensammer G, Ulmer H, Morgenthaler N, Hasibeder W, Dunser MW: The vasopressin and copeptin response in patients with vasodilatory shock after cardiac surgery: a prospective, controlled study. Intensive Care Med 2009, 35(3):489-497.

12. Morgenthaler NG, Muller B, Struck J, Bergmann A, Redl H, Christ-Crain M: Copeptin, a stable peptide of the arginine vasopressin precursor, is elevated in hemorrhagic and septic shock. Shock 2007, 28(2):219-226.

13. Russell JA: Vasopressin and its copilot copeptin in sepsis and septic shock. Crit Care Med 2009, 37(2):749-750.

14. Muller B, Morgenthaler N, Stolz D, Schuetz P, Muller C, Bingisser R, Bergmann A, Tamm M, Christ-Crain M: Circulating levels of copeptin, a novel biomarker, in lower respiratory tract infections. Eur J Clin Invest 2007, 37(2):145-152.

15. Wellmann S, Benzing J, Cippa G, Admaty D, Creutzfeldt R, Arlettaz Mieth R, Beinder E, Lapaire O, Morgenthaler NG, Haagen U, et al: High Copeptin Concentrations in Umbilical Cord Blood after Vaginal Delivery and Birth Acidosis. J Clin Endocrin Me tab 2010, 95(11):5091-6.

16. Lawn JE, Cousens S, Zupan J: 4 million neonatal deaths: when? Where? Why? Lancet 2005, 365(9462):891-900

17. van den Hoogen A, Gerards LJ, Verboon-Maciolek MA, Fleer A, Krediet TG: Long-term trends in the epidemiology of neonatal sepsis and antibiotic susceptibility of causative agents. Neonatology 2010, 97(1):22-28.

18. van Rossum AM, Wulkan RW, Oudesluys-Murphy AM: Procalcitonin as an early marker of infection in neonates and children. Lancet Infect Dis 2004, 4(10):620-630.

19. Lawn J, Cousens S, Zupan J: 4 million neonatal deaths: When? Where? Why? The Lancet 2005, 365(9462):891-900.

20. Azzopardi DV, Strohm B, Edwards AD, Dyet L, Halliday HL, Juszczak E, Kapellou O, Levene M, Marlow N, Porter E, et al: Moderate hypothermia to treat perinatal asphyxial encephalopathy. N Engl J Med 2009, 361(14):1349-1358.

21. Stoll BJ, Hansen N, Fanaroff AA, Wright $L L$, Carlo WA, Ehrenkranz RA Lemons JA, Donovan EF, Stark AR, Tyson JE, et al: Changes in pathogens causing early-onset sepsis in very-low-birth-weight infants. N Engl J Med 2002, 347(4):240-247.

22. Kaukola T, Herva R, Perhomaa M, Paakko E, Kingsmore S, Vainionpaa L, Hallman M: Population cohort associating chorioamnionitis, cord inflammatory cytokines and neurologic outcome in very preterm, extremely low birth weight infants. Pediatr Res 2006, 59(3):478-483.

23. Sarnat HB, Sarnat MS: Neonatal encephalopathy following fetal distress. A clinical and electroencephalographic study. Arch Neurol 1976, 33(10):696-705.

24. Morgenthaler NG, Müller B, Struck J, Bergmann A, Redl H, Christ-Crain M: Copeptin, a Stable Peptide of the Arginine Vasopressin Precursor, Is Elevated in Hemorrhagic and Septic Shock. Shock 2007, 28(2):219-226.

25. Westermann I, Dunser MW, Haas T, Jochberger S, Luckner G, Mayr VD, Wenzel V, Stadlbauer KH, Innerhofer P, Morgenthaler N, et al: Endogenous vasopressin and copeptin response in multiple trauma patients. Shock 2007, 28(6):644-649.

26. Reichlin T, Hochholzer W, Stelzig C, Laule K, Freidank H, Morgenthaler NG, Bergmann A, Potocki M, Noveanu M, Breidthardt T, et al: Incremental value of copeptin for rapid rule out of acute myocardial infarction. J Am Coll Cardiol 2009, 54(1):60-68

27. Harris TA, Healy GN, Colditz PB, Lingwood BE: Associations between serum cortisol, cardiovascular function and neurological outcome following acute global hypoxia in the newborn piglet. Stress 2009, 12(4):294-304

28. Vogl SE, Worda C, Egarter C, Bieglmayer C, Szekeres T, Huber J, Husslein P: Mode of delivery is associated with maternal and fetal endocrine stress response. BJOG 2006, 113(4):441-445.

29. Ezgu FS, Atalay Y, Gucuyener K, Tunc S, Koc E, Ergenekon E, Tiras U: Neuron-specific enolase levels and neuroimaging in asphyxiated term newborns. J Child Neurol 2002, 17(11):824-829. 
30. Gazzolo D, Abella R, Marinoni E, di lorio R, Li Volti G, Galvano F, Frigiola A, Temporini F, Moresco L, Colivicchi M, et al: New markers of neonatal neurology. J Matern Fetal Neonatal Med 2009, 22(Suppl 3):57-61.

31. Torrance HL, Benders MJ, Derks JB, Rademaker CM, Bos AF, Van Den Berg P, Longini $\mathrm{M}$, Buonocore $\mathrm{G}$, Venegas $\mathrm{M}$, Baquero $\mathrm{H}$, et al: Maternal allopurinol during fetal hypoxia lowers cord blood levels of the brain injury marker S-100B. Pediatrics 2009, 124(1):350-357.

\section{Pre-publication history}

The pre-publication history for this paper can be accessed here: http://www.biomedcentral.com/1471-2431/11/38/prepub

doi:10.1186/1471-2431-11-38

Cite this article as: Schlapbach et al:: Copeptin concentration in cord

blood in infants with early-onset sepsis, chorioamnionitis and perinatal asphyxia. BMC Pediatrics 2011 11:38.

\section{Submit your next manuscript to BioMed Central} and take full advantage of:

- Convenient online submission

- Thorough peer review

- No space constraints or color figure charges

- Immediate publication on acceptance

- Inclusion in PubMed, CAS, Scopus and Google Scholar

- Research which is freely available for redistribution

Submit your manuscript at www.biomedcentral.com/submit 